\title{
Urinary Excretion of 6-Sulfatoxymelatonin, the Main Metabolite of Melatonin, and Mortality in Stable Outpatient Renal Transplant Recipients
}

\author{
Anna van der Veen ${ }^{1, *}$, Isidor Minović ${ }^{1,2}{ }^{2}$ Martijn van Faassen ${ }^{1}$, António W. Gomes-Neto ${ }^{2}{ }^{(0)}$ \\ Stefan P. Berger ${ }^{2}$, Stephan J. L. Bakker ${ }^{2}$ and Ido P. Kema ${ }^{1}$ \\ 1 Department of Laboratory Medicine, University of Groningen, University Medical Center Groningen, \\ 9713 GZ Groningen, The Netherlands; i.minovic@umcg.nl (I.M.); h.j.r.van.faassen@umcg.nl (M.v.F.); \\ i.p.kema@umcg.nl (I.P.K.) \\ 2 Department of Internal Medicine, University of Groningen, University Medical Center Groningen, \\ 9713 GZ Groningen, the Netherlands; a.w.gomes.neto@umcg.nl (A.W.G.-N.); s.p.berger@umcg.nl (S.P.B.); \\ s.j.l.bakker@umcg.nl (S.J.L.B.) \\ * Correspondence: a.van.der.veen03@umcg.nl; Tel.: +31-50-361-0363
}

Received: 27 January 2020; Accepted: 12 February 2020; Published: 14 February 2020

\begin{abstract}
Melatonin is a multifaceted hormone which rises upon the onset of darkness. Pineal synthesis of melatonin is known to be disturbed in patients with end-stage renal disease, but it is not known if its production is restored to normal after successful renal transplantation. We hypothesized that urinary excretion of 6-sulfatoxymelatonin, the major metabolite of melatonin, is lower in renal transplant recipients (RTRs) compared to healthy controls and that this is associated with excess mortality. Urinary 6-sulfatoxymelatonin was measured via LC-MS/MS in 701 stable outpatient RTRs and 285 healthy controls. Median urinary 6-sulfatoxymelatonin in RTR was $13.2 \mathrm{nmol} / 24 \mathrm{~h}$, which was $47 \%$ lower than in healthy controls. Urinary 6-sufatoxymelatonin appeared undetectable in the majority of 36 RTRs with diabetic nephropathy as primary renal disease. Therefore, this subgroup was excluded from further analyses. Of the remaining 665 RTRs, during 5.4 years of follow-up, 110 RTRs died, of whom 38 died due to a cardiovascular cause. In Cox-regression analyses, urinary 6-sulfatoxymelatonin was significantly associated with all-cause mortality $(0.60(0.44-0.81), p=0.001)$ and cardiovascular mortality $(0.49(0.29-0.84), p=0.009)$, independent of conventional risk factors and kidney function parameters. Based on these results, evaluation and management of melatonin metabolism could be considered for improvement of long-term outcomes in RTRs.
\end{abstract}

Keywords: 6-Sulfatoxymelatonin; Melatonin; Kidney Transplantation; Urinary Excretion; LC-MS/MS

\section{Introduction}

Many patients with end-stage renal disease (ESRD) experience sleep-related problems. Although renal transplantation is the preferred treatment for end-stage renal failure, the quality of sleep in these patients remains lower compared to the general population [1]. A combination of factors, including chronic treatment with immunosuppressive medication, comorbidities, depression, and stress have been indicated to adversely affect the quality of sleep in renal transplant recipients (RTRs) [2,3]. Importantly, poor sleep quality has been implicated as a contributor to poor long-term outcomes and premature mortality in patients with chronic kidney disease $[4,5]$.

Melatonin is a multifaceted hormone that rises upon the onset of darkness. Melatonin is synthesized from tryptophan and serotonin in the pineal gland. Melatonin present in the circulation plays a vital role in the circadian rhythm and has been associated with the sleep-wake cycle [6,7]. After entering systemic circulation, where melatonin exerts its multiple functions via $G$ protein-coupled 
melatonin-receptors, melatonin is metabolized by the liver, where approximately $90 \%$ of melatonin is hydroxylated and subsequently conjugated to form 6-sulfatoxymelatonin (6-SM), which is excreted in the urine [8,9]. The $24 \mathrm{~h}$ urinary 6-SM excretion therefore provides an integrated measurement of melatonin production in circulation over a day [10].

Melatonin production has been shown to be severely disturbed in patients with ESRD [11]. It is not known whether pineal melatonin production is restored to normal after successful renal transplantation. Since poor sleep quality has been associated with poor long-term outcomes and mortality in patients with chronic kidney disease, we hypothesized that low endogenous melatonin production in RTRs is associated with increased risk for mortality in these patients. We therefore aimed to compare $24 \mathrm{~h}$ urinary 6-SM excretion between RTRs and healthy controls and to prospectively analyse the association of $24 \mathrm{~h}$ urinary 6-SM levels with mortality in a large cohort of stable outpatient RTRs, making use of an existing biobank. In these latter analyses, diabetes, in particular diabetic nephropathy, and the use of beta-blockers were of particular interest, because both have been reported to be associated with low endogenous melatonin synthesis and low urinary 6-SM excretion [12-15].

\section{Materials and Methods}

\subsection{Study Population}

For this study, we performed post-hoc analysis on an existing biobank underlying this prospective cohort study. The cohort comprised RTRs with a graft that had been stable for at least one year. The RTRs visited the outpatient clinic of the University Medical Center Groningen (UMCG), the Netherlands, between November 2008 and June 2010, as described previously [16]. Out of the 817 eligible RTRs, 707 were included and written informed consents were obtained. The median time after transplantation was 5.5 (interquartile range (IQR) 2.0-12.1) years (transplant vintage). For 701 out of the 707 RTRs, $24 \mathrm{~h}$ urine samples were available for 6-SM analysis. As control group, 285 healthy controls were included. These controls were kidney donors who participated in a screening program and were included in another cohort. None of the donors had a history of kidney disease, diabetes, or cardiovascular disease. The Medical Ethical Committee of the UMCG approved the study protocol (METc 2008/186) according to the principals of the Declaration of Helsinki.

\subsection{Data and sample collection}

Fasting blood samples of RTRs were drawn in the morning on the day following collection of $24 \mathrm{~h}$ urine samples. Routine laboratory analysis in plasma and urine were performed shortly after collection, according to standard laboratory procedures. Plasma and urine samples were stored at $-80^{\circ} \mathrm{C}$. Detailed information on the laboratory measurements in this RTR-cohort is described elsewhere [17]. The UMCG renal transplantation database provided information such as date of transplantation, primary renal disease, history of acute rejection, dialysis vintage, and donor status. Data on causes of death were obtained from patients' records. The glomerular filtration rate (eGFR) was estimated using an equation that included both creatinine and cystatin C [18]. The use of medication and vitamin supplementation were recorded according to patients' medical records.

\subsection{Urinary 6-SM Laboratory Measurements}

6-SM was measured in $24 \mathrm{~h}$ urine samples via isotope dilution liquid chromatography (Pursuit XRS Diphenyl column, Agilent, Santa Clara, CA, USA) combined with tandem mass spectrometry (SPE-LC-MS/MS) (Symbiosis ${ }^{\mathrm{TM}}$ Pharma system, Spark Holland, Emmen, the Netherlands and XEVO TQS, Waters, Milford, MA, USA). The urine samples were not stabilized and the $\mathrm{pH}$ was not altered. 6-SM-d4 (CacheSyn Inc., Mississauga, Canada) was used as the internal standard. The inter-assay coefficient of variation was $<5.4 \%$. The lower limit of quantitation (LLOQ) for 6-SM in urine was $0.20 \mathrm{nmol} / \mathrm{L}$. If a urinary 6-SM value was below the LLOQ, the value was set to $0.20 \mathrm{nmol} / \mathrm{L}$ to allow for inclusion of these subjects in further analysis. 


\subsection{Clinical Endpoints}

The primary endpoint of this study was all-cause mortality related to $24 \mathrm{~h}$ urinary 6-SM output in RTRs. A secondary endpoint was cardiovascular mortality. Cardiovascular mortality included death by cerebrovascular disease, ischemic heart disease, heart failure, or sudden cardiac death according to the International Classification of Diseases, 9th revision (ICD-9), codes 410-447. Endpoints were recorded until the end of September 2015 [19].

\subsection{Statistical Analysis}

Statistical analyses were performed with SPSS statistics version 22.0 (IBM, Armonk, NY, USA). The data are presented as mean \pm standard deviation (SD), as median (IQR) or as number (percentage, $n \%)$. A $p$-value $<0.05$ was considered statistically significant. Normal distribution was tested with histograms and probability plots. Non-normally distributed data were transformed to ${ }^{10} \log$, in order to meet the assumptions for linear regression analysis.

Differences between RTRs and healthy controls were determined using univariable regression analyses. Since $24 \mathrm{~h}$ urinary 6-SM excretion may be confounded by age, sex, and eGFR as an indication for kidney function, additional multivariable regression analyses were performed, expressed as standardized $\beta$. Standardized $\beta$ allows the comparison of variables with different units, since standardized $\beta$ makes use of the SD. The higher the standardized $\beta$, the stronger the effect.

As the presence of diabetic nephropathy as primary renal disease and the use of beta-blockers have been reported to be associated with particularly low urinary 6-SM excretion [12-15], we separately evaluated whether they were associated with a particularly high frequency of undetectable urinary 6-SM concentrations, which might preclude further analyses on urinary 6-SM excretion in these subgroups.

The RTR population was divided into tertiles of $24 \mathrm{~h}$ urinary 6-SM excretion. To identify associations of urinary 6-SM excretion with baseline variables, univariable linear regression analyses were performed ( $p$-trend). To identify independent determinants of $24 \mathrm{~h}$ urinary 6-SM excretion, multivariable linear regression analyses were performed. Multivariable linear regression models were constructed using backward selection, and included variables that were associated with urinary 6 -SM excretion in the univariable analysis with a $p$-value of $<0.20$. For related variables, the variable with the strongest association was included in the analysis. All variables were entered into the linear regression model. The variable with the highest $p$-value was excluded and the regression analysis was performed again without this variable. This was repeated until all the variables had a $p$-value below the significance level of 0.05 .

To test whether urinary 6-SM excretion was associated with all-cause and cardiovascular mortality, the tertiles of urinary 6-SM excretion were analyzed by Kaplan-Meier analysis with log-rank testing. To report the number of RTRs still at risk of an event at the follow-up time-points of $0,1,2,3,4,5$, and 6 years, "life tables" were run. Subsequently, Cox proportional hazard regression analyses, with adjustment for potential confounders, were performed on the continuous variable of urinary 6-SM excretion, including the tertiles. The first tertile served as the reference group, and the hazard ratio (HR) was therefore set to 1 . An HR lower than the reference value of 1 indicated a poorer outcome concerning mortality. Prospective associations were cumulatively adjusted for potential confounders in five models, to avoid overfitting and to keep the number of predictors in proportion to the number of events. Confounders adjusted for included age and sex (Model 2), waist circumference and smoking (Model 3), diabetes and serum albumin (Model 4), and finally beta-blocker use, eGFR, acute rejection, donor status (living or deceased), and proteinuria (Model 5). Proportionality of hazards was tested by examining the Schoenfeld residuals.

\section{Results}

Baseline characteristics of the 701 RTRs and 285 healthy controls are shown in Table 1. Median (IQR) $24 \mathrm{~h}$ urinary 6-SM excretion in RTRs was $13.2 \mathrm{nmol} / 24 \mathrm{~h}(3.5-31.2 \mathrm{nmol} / 24 \mathrm{~h})$, which was $47 \%$ 
lower than in the healthy controls $(24.9(11.6-41.2) \mathrm{nmol} / 24 \mathrm{~h})$. Of the RTR, $81(12 \%)$ had urinary 6-SM concentrations below the detection limits, compared to $3(1 \%)$ in the healthy controls. In multivariable linear regression analyses, the difference in urinary 6-SM excretion between RTRs and healthy controls appeared to be independent of age and sex and partly independent of eGFR.

Table 1. Baseline characteristics comparison between healthy controls and RTR ${ }^{1 .}$

\begin{tabular}{lccccc}
\hline & & & \multicolumn{2}{c}{ Standardized B } \\
& Healthy Controls & RTR & Model 1 & Model 2 & Model 3 \\
& $n=285$ & $n=701$ & & & \\
\hline 6-SM (nmol/24 h) & $24.9(11.6-41.2)^{1}$ & $13.2(3.5-31.2)$ & $-0.244^{* * *}$ & $-0.276^{* * *}$ & $-0.062^{* *}$ \\
6-SM (nmol/L) & $9.9(4.5-17.9)$ & $5.2(1.5-12.7)$ & $-0.152^{* * *}$ & $-0.180^{* * *}$ & $-0.071^{* *}$ \\
Urine volume (L) & $2.5(2.0-3.0)$ & $2.4(1.9-2.8)$ & $-0.069^{*}$ & $-0.064^{*}$ & 0.000 \\
Undetectable 6-SM levels, $n \%$ & $3(1)$ & $81(12)$ & $0.169^{* * *}$ & $0.178^{* * *}$ & 0.024 \\
Age, years & $53.3 \pm 10.8^{2}$ & $53.0 \pm 12.7$ & -0.019 & & \\
Male sex, $n^{*}$ eGFR, mL/min per 1.73 m ${ }^{2}$ & $135(47)$ & $399(57)$ & $-0.089^{* *}$ & & \\
Total cholesterol, nmol/L & $90.9 \pm 14.1$ & $45.0 \pm 18.7$ & $-0.749^{* * *}$ & $-0.758^{* * *}$ & \\
Waist-circumference, cm & $5.4 \pm 1.1$ & $5.1 \pm 1.1$ & $-0.106^{* * *}$ & $-0.095^{* *}$ & $-0.064^{* * *}$ \\
hsCRP, mg/L & $91.1 \pm 10.1$ & $98.6 \pm 14.7$ & $0.216^{* * *}$ & $0.220^{* * *}$ & $0.066^{* * *}$ \\
Serum glucose, mmol/L & $1.1(0.6-2.3)$ & $1.6(0.7-4.6)$ & $0.113^{* * *}$ & $0.133^{* * *}$ & -0.002 \\
HbA1c, \% & $5.4 \pm 0.6$ & $5.7 \pm 1.8$ & 0.060 & 0.056 & $0.046^{*}$ \\
PTH, pmol/L & $5.6 \pm 0.3$ & $6.0 \pm 0.8$ & $0.245^{* * *}$ & $0.258^{* * *}$ & $0.135^{* * *}$ \\
Beta-blocker use, $\boldsymbol{n}^{*} \%$ & $3.3(2.6-4.2)$ & $8.9(5.9-14.7)$ & $0.552^{* * *}$ & $0.553^{* * *}$ & $0.192^{* * *}$ \\
\hline
\end{tabular}

${ }^{1}$ Differences between groups were analyzed with univariable and multivariable linear regression analyses, for which the standardized $\beta$ s are shown $\left({ }^{*} p<0.05,{ }^{* *} p<0.01,{ }^{* * *} p<0.001\right)$. Model 1 was a crude model, Model 2 was adjusted for age and sex. Model 3 was adjusted for Model 2 and eGFR; ${ }^{1}$ Median (IQR); ${ }^{2}$ Mean \pm SD. Abbreviations: 6-SM: 6-sulfatoxymelatonin; eGFR: estimated glomerular filtration rate; HbA1c: glycated hemoglobin; hsCRP: high-sensitivity C-reactive protein; PTH: parathyroid hormone.

In the 36 RTRs with diabetic nephropathy as primary renal disease, the frequency of urinary 6-SM below the detection limit was $22(61 \%)$, which was much higher than the frequency of $59(9 \%)$ in the rest of the RTRs. In the 422 RTRs that were using beta-blockers, the frequency of urinary 6-SM below the detection limit was $55(13 \%)$, which was higher than the frequency of $4(1.6 \%)$ in the rest of the RTRs. Because of the very high frequency of urinary 6-SM concentrations below the detection limit, subjects with diabetic nephropathy were excluded from further analyses. Baseline characteristics of the remaining 665 RTRs, presented according to tertiles of urinary 6-SM excretion, are shown in Table 2. RTRs in the highest tertile of urinary 6-SM excretion were significantly younger, had a lower waist circumference, experienced less acute rejection, had higher eGFR levels as a parameter for kidney function, and had a lower prevalence of diabetes, also marked by lower serum glucose and $\mathrm{HbA1c}$ levels, and less use of antidiabetic medication. Furthermore, the urinary 6-SM excretion levels were significantly lower in RTRs who had received a kidney from a deceased donor compared to a living donor (10.2 nmol/24 h (IQR 3.2-25.8 nmol/24 h) and $20.5 \mathrm{nmol} / 24 \mathrm{~h}$ (IQR 9.1-39.2 nmol/24 h) respectively, $p<0.001$, Mann-Whitney $\mathrm{U}$ test). 
Table 2. Baseline patient characteristics of the stable RTRs (without diabetic nephropathy) presented as tertiles of urinary 6-sulfatoxymelatonin 1 .

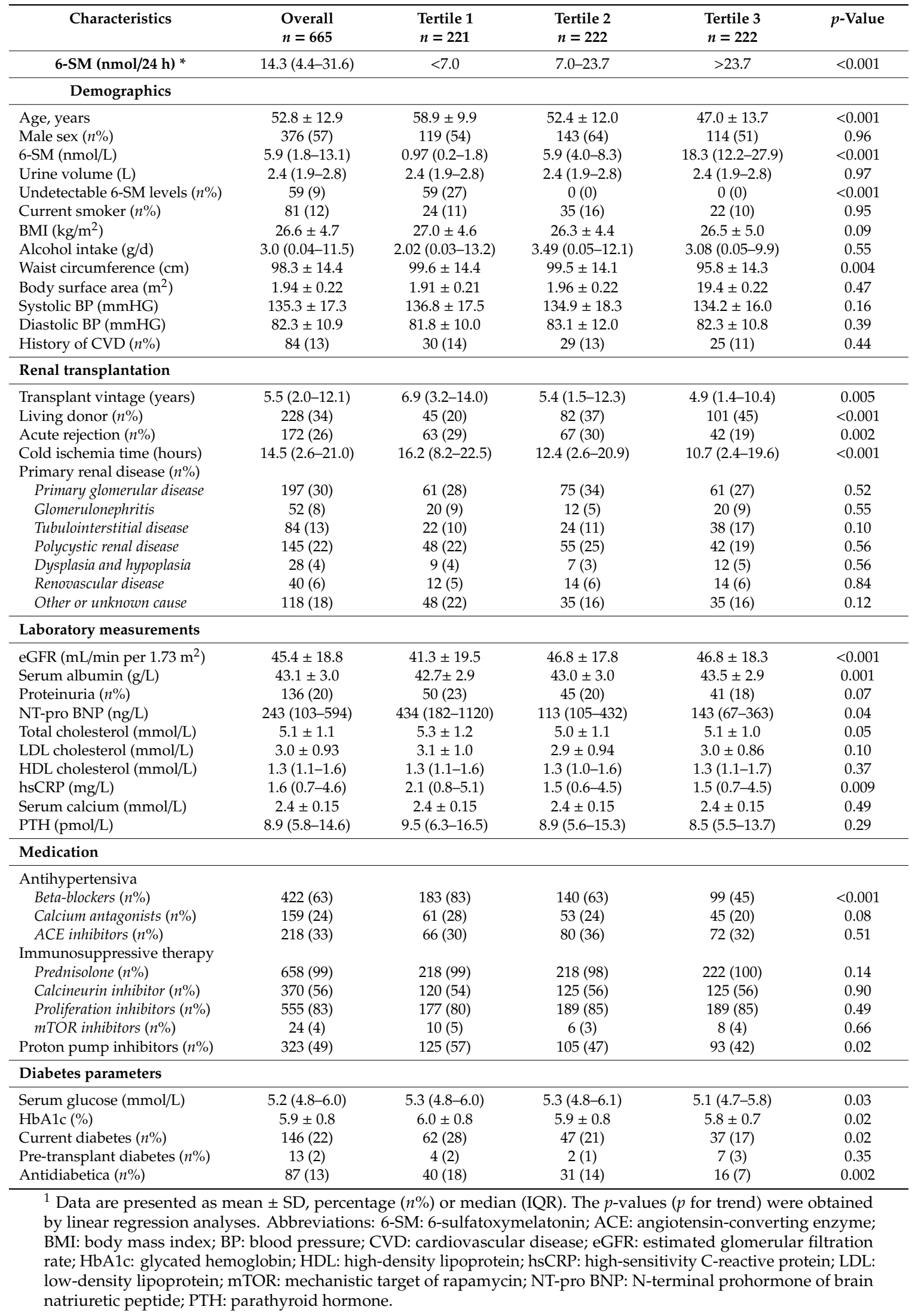


For the assessment of independent associations of urinary 6-SM excretion parameters, multivariable linear regression analysis with backward elimination was performed. It was found that age, history of acute rejection, and beta-blocker use were inversely associated with urinary 6-SM excretion, whereas living donor status was positively associated, as shown in Table 3.

Table 3. Univariable and multivariable associations of 6-sulfatoxymelatonin excretion with clinical parameters in 665 RTRs (without diabetic nephropathy) 1.

\begin{tabular}{|c|c|c|c|c|}
\hline \multicolumn{5}{|c|}{ Urinary 6-Sulfatoxymelatonin Excretion } \\
\hline & \multicolumn{2}{|c|}{ Univariable } & \multicolumn{2}{|c|}{ Multivariable } \\
\hline & Standardized $\beta$ & p-Value & Standardized $\beta$ & $p$-Value \\
\hline \multicolumn{5}{|l|}{ Demographics } \\
\hline Age (years) & -0.351 & $<0.001$ & -0.282 & $<0.001$ \\
\hline Sex & -0.002 & 0.96 & & \\
\hline Waist circumference $(\mathrm{cm})$ & -0.115 & 0.004 & & \\
\hline $\mathrm{SBP}(\mathrm{mmHG})$ & -0.055 & 0.16 & & \\
\hline \multicolumn{5}{|l|}{ Renal transplantation } \\
\hline Transplant vintage (years) & -0.110 & 0.005 & & \\
\hline Living donor & 0.224 & $<0.001$ & 0.130 & $<0.001$ \\
\hline Acute rejection & -0.118 & 0.002 & -0.082 & 0.02 \\
\hline Cold ischemia time, hours & -0.182 & $<0.001$ & & \\
\hline \multicolumn{5}{|l|}{ Primary renal disease } \\
\hline Tubulointerstitial disease & 0.065 & 0.10 & & \\
\hline Other or unknown cause & -0.060 & 0.12 & & \\
\hline \multicolumn{5}{|l|}{ Laboratory measurements } \\
\hline eGFR $\left(\mathrm{mL} / \mathrm{min}\right.$ per $\left.1.73 \mathrm{~m}^{2}\right)$ & 0.153 & $<0.001$ & & \\
\hline Serum albumin $(\mathrm{g} / \mathrm{L})$ & 0.130 & 0.001 & & \\
\hline Proteinuria $(n \%)$ & -0.070 & 0.07 & & \\
\hline NT-pro BNP (ng/L) & -0.081 & 0.04 & & \\
\hline Total cholesterol (nmol/L) & -0.077 & 0.05 & & \\
\hline hsCRP (mg/L) & -0.102 & 0.009 & & \\
\hline \multicolumn{5}{|l|}{ Medication } \\
\hline Beta-blockers & -0.324 & $<0.001$ & -0.264 & $<0.001$ \\
\hline Prednisolone (mg/d) & 0.057 & 0.14 & & \\
\hline Proton-pump inhibitors & -0.094 & 0.02 & & \\
\hline \multicolumn{5}{|l|}{ Diabetes parameters } \\
\hline Serum glucose $(\mathrm{mmol} / \mathrm{L})$ & -0.087 & 0.03 & & \\
\hline $\operatorname{HbA1c}(\%)$ & -0.093 & 0.02 & & \\
\hline Current diabetes & -0.089 & 0.02 & & \\
\hline Antidiabetica & -0.118 & 0.002 & & \\
\hline
\end{tabular}

After a median follow-up of 5.4 (4.8-6.1) years, 110 out of 665 RTRs had died (17\%), of whom 38 $(35 \%)$ were due to a cardiovascular cause, including cerebrovascular disease, ischemic heart disease, heart failure, and sudden cardiac death. Kaplan-Meier analysis showed increased risk of all-cause mortality with decreasing tertiles of urinary 6-SM excretion, as shown in Figure 1. Similar results were observed for cardiovascular mortality, both with log-rank $p<0.001$. 

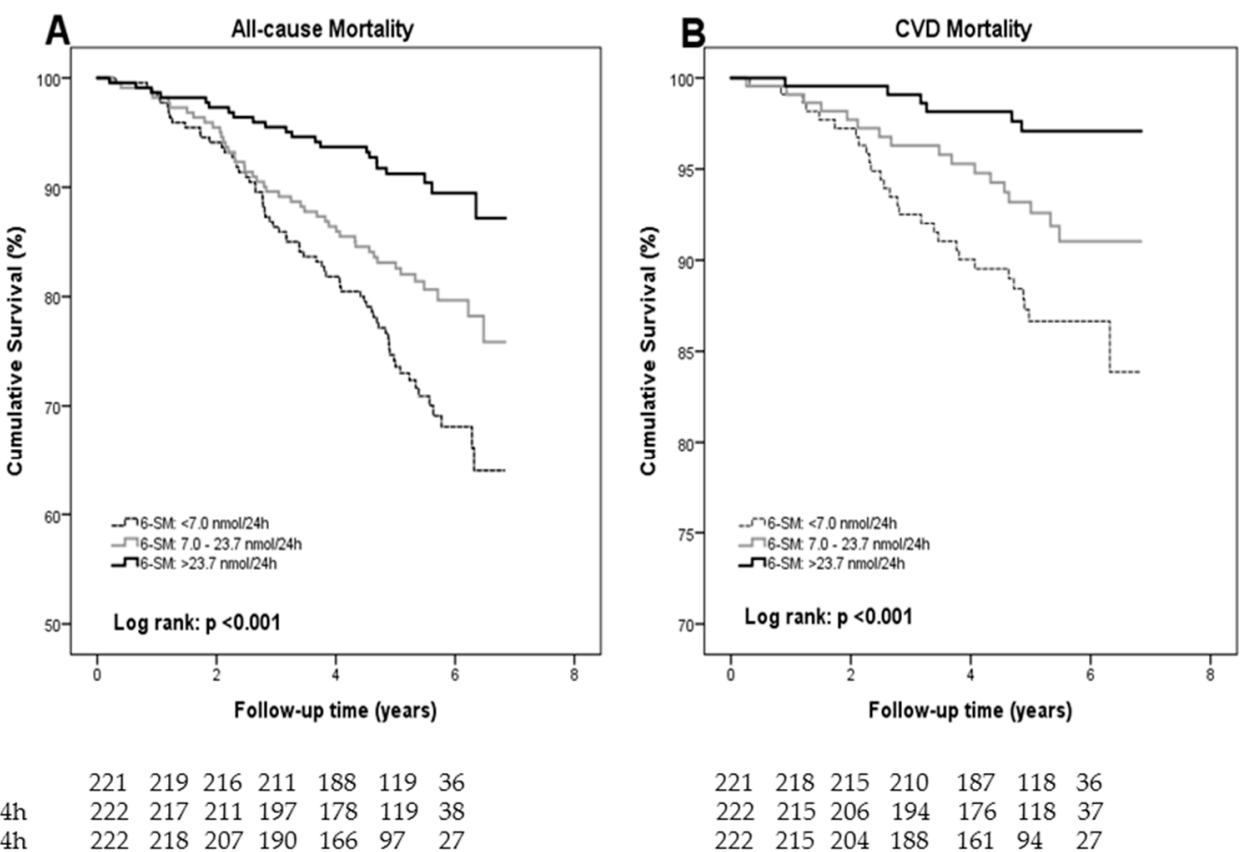

Patients at risk: $6-\mathrm{SM}<0.7 \mathrm{nmol} / 24 \mathrm{~h}$ 6-SM $7.0-23.7 \mathrm{nmol} / 24 \mathrm{~h}$ 6-SM $23.7-7.0 \mathrm{nmol} / 24 \mathrm{~h}$

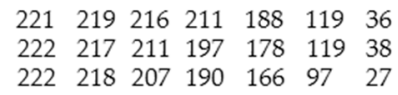

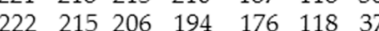

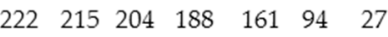

Figure 1. Kaplan-Meier curves for mortality of RTRs according to the tertiles of urinary 6-sulfatoxymelatonin excretion. (A) All-cause mortality, and (B) cardiovascular mortality. Below the horizontal axis, the numbers of patients still at risk of an event at the follow-up time-points $0,1,2,3,4$, 5, and 6 years are shown. Abbreviations: 6-SM: 6-sulfatoxymelatonin, CVD: cardiovascular disease.

Cox regression analyses revealed that urinary 6-SM excretion, as a continuous variable, was significantly inversely associated with all-cause mortality (HR $(95 \%$ confidence interval $(\mathrm{CI}))=0.60$ $(0.44-0.81), p=0.001)$, independent of potential confounders, including age, sex, waist circumference, smoking, diabetes, serum albumin, eGFR, acute rejection, proteinuria, donor status, and beta-blocker use, as shown in Table 4. Analysis according to the tertiles of urinary 6-SM excretion revealed that RTRs in the lowest tertile (i.e., lowest urinary 6-SM levels) had a higher risk of mortality, compared to RTRs in the intermediate (HR $(95 \% \mathrm{CI})=0.80(0.51-1.26))$ and highest tertiles $(\mathrm{HR}(95 \% \mathrm{CI})=0.43$ $(0.24-0.77))$.

Table 4. Cox proportional hazards regression analysis for the association of 6-sulfatoxymelatonin with all-cause and cardiovascular mortality in RTRs (without diabetic nephropathy) ${ }^{1 .}$

\begin{tabular}{|c|c|c|c|c|c|c|c|}
\hline & Tertile 1 & Tertile 2 & & Tertile 3 & & Overall & \\
\hline & $H R(95 \% C I)$ & $H R(95 \% C I)$ & $p$-Value & $H R(95 \% C I)$ & $p$-Value & $H R(95 \% C I)$ & $p$-Value \\
\hline \multicolumn{8}{|l|}{$\begin{array}{l}\text { All-cause } \\
\text { mortality }\end{array}$} \\
\hline Model $1^{\mathrm{c}}$ & 1.0 (Ref) & $0.59(0.39-0.90)$ & 0.01 & $0.27(0.16-0.46)$ & $<0.001$ & $0.45(0.34-0.59)$ & $<0.001$ \\
\hline Model $2^{\mathrm{d}}$ & 1.0 (Ref) & $0.81(0.53-1.24)$ & 0.34 & $0.45(0.26-0.78)$ & 0.004 & $0.60(0.45-0.80)$ & 0.001 \\
\hline Model $3^{\mathrm{e}}$ & 1.0 (Ref) & $0.76(0.50-1.12)$ & 0.20 & $0.44(0.25-0.76)$ & 0.003 & $0.60(0.45-0.79)$ & $<0.001$ \\
\hline Model $4^{\mathrm{f}}$ & 1.0 (Ref) & $0.73(0.48-1.12)$ & 0.15 & $0.42(0.24-0.73)$ & 0.002 & $0.58(0.44-0.77)$ & $<0.001$ \\
\hline Model $5^{g}$ & 1.0 (Ref) & $0.80(0.51-1.26)$ & 0.34 & $0.43(0.24-0.77)$ & 0.004 & $0.60(0.44-0.81)$ & 0.001 \\
\hline \multicolumn{8}{|c|}{$\begin{array}{l}\text { Cardiovascular } \\
\text { mortality b }\end{array}$} \\
\hline Model $1^{\mathrm{C}}$ & 1.0 (Ref) & $0.61(0.30-1.21)$ & 0.16 & $0.21(0.08-0.57)$ & 0.002 & $0.42(0.27-0.67)$ & $<0.001$ \\
\hline Model $2 \mathrm{~d}$ & 1.0 (Ref) & $0.78(0.38-1.58)$ & 0.48 & $0.33(0.12-0.90)$ & 0.03 & $0.52(0.32-0.86)$ & 0.01 \\
\hline Model $3^{\mathrm{e}}$ & 1.0 (Ref) & $0.69(0.34-1.41)$ & 0.31 & $0.32(0.12-0.88)$ & 0.03 & $0.52(0.32-0.86)$ & 0.01 \\
\hline Model $4 \mathrm{f}$ & 1.0 (Ref) & $0.63(0.31-1.29)$ & 0.20 & $0.28(0.10-0.76)$ & 0.01 & $0.48(0.29-0.78)$ & 0.003 \\
\hline Model $5^{g}$ & 1.0 (Ref) & $0.70(0.33-1.51)$ & 0.37 & $0.27(0.09-0.78)$ & 0.01 & $0.49(0.29-0.84)$ & 0.009 \\
\hline
\end{tabular}

${ }^{1}$ Data are presented as hazard ratio (HR) with the $95 \% \mathrm{CI}$ and $p$-values according to the tertiles of 6-SM and the continuous data. ${ }^{\mathrm{a}} \mathrm{N}_{\text {events }} / \mathrm{N}_{\text {total }}=110 / 665 ;{ }^{\mathrm{b}} \mathrm{N}_{\text {events }} / \mathrm{N}_{\text {total }}=38 / 665 ;{ }^{\mathrm{c}}$ Model 1: crude; ${ }^{\mathrm{d}}$ Model 2: adjusted for age, sex; ${ }^{\mathrm{e}}$ Model 3: waist circumference, smoking; ${ }^{\mathrm{f}}$ Model 4: current diabetes, serum albumin; ${ }^{\mathrm{g}}$ Model 5: eGFR, acute rejection, proteinuria, living donor, beta-blocker. Abbreviations: 6-SM: 6-sulfatoxymelatonin; CI: confidence interval; HR: hazard ratio. 
Cox regression analysis of urinary 6-SM excretion with cardiovascular mortality also displayed a significant association, independent of the potential confounders, $(\mathrm{HR}(95 \% \mathrm{CI})=0.49(0.29-0.84)$, $p=0.009)$. Analysis of the tertiles of urinary 6-SM excretion demonstrated an increased cardiovascular-related mortality risk of RTRs in the lowest tertile compared to the middle tertile (HR $(95 \% \mathrm{CI})=0.70(0.33-1.51))$ and highest tertile $(\mathrm{HR}(95 \% \mathrm{CI})=0.27(0.09-0.78))$, in line with what was found for all-cause mortality.

\section{Discussion}

In this study, we found that $24 \mathrm{~h}$ urinary 6-SM excretion, measured with a reliable isotope dilution LC-MS/MS method, was much lower in stable outpatient RTRs than in healthy controls and that low urinary 6-SM excretion was significantly and independently associated with increased risk of premature mortality, particularly cardiovascular mortality.

The role of melatonin during (end-stage) kidney disease and transplantation is increasingly being studied $[3,11]$. In the case of renal transplantation, a study by Russcher et al. showed that melatonin levels measured in saliva did not improve 3 months after kidney transplantation, and concluded that the time-span after transplantation was too short to see a possible improvement [20]. Burkhalter et al. also measured saliva melatonin in 29 stable RTRs more than 1 year post-transplantation. In these RTRs with sleep-wake disturbances, they found low melatonin levels, mainly in the RTRs without dim-light melatonin onset, and this was related to health impairment in this group [21]. In line with our study results, they found a high percentage of RTRs with fairly low to no melatonin production. These studies showed that restoration of melatonin levels does not occur shortly after transplantation, and our study showed that after a median of 5.5 years following transplantation, the levels are still clearly reduced compared to healthy controls.

Lower urinary 6-SM levels in RTRs compared to healthy controls seem to be partly explained by kidney function, as shown by multivariable linear regression analyses. Besides decreased kidney function, several factors could result in reduced urinary 6-SM in the RTR population. One factor known to reduce melatonin levels is pineal calcification, relatively common with increasing age [22]. A study by Kunz et al. showed reduced urinary 6-SM excretion with increasing pineal calcification [23]. As expected, our RTRs had clearly increased levels of parathyroid hormone (PTH). PTH results in increased mobilization of calcium from bones and promotes reabsorption of calcium in the kidneys [24]. Combined with the reduced renal function in RTRs, less calcium is excreted via the urine; it can then precipitate in soft tissue where it can cause vascular calcification $[25,26]$. It could be possible that the pineal gland is affected by the calcium deposit. However not much is known yet about the link between PTH and pineal calcification. Another important, extrinsic factor that could influence melatonin levels is the use of medication, and in particular beta-blockers [12,27]. Beta-blockers reduce melatonin production by blocking the adrenergic beta- 1 receptor [12]. Inhibition of this receptor prevents the activation of serotonin $\mathrm{N}$-acetyltransferase, necessary for the conversion of serotonin to melatonin. Of the RTRs in this study, $63 \%$ used beta-blockers to control hypertension. The cross-sectional data of RTRs on beta-blockers showed significantly lower levels of urinary 6-SM, however, correction for beta-blockers as a potential confounder in prospective analysis did not influence the association of urinary 6-SM excretion with mortality. Additionally, in our cohort of stable RTRs, it was found that patients who had received a kidney from a living donor had higher urinary 6-SM levels compared to patients that had received a kidney from a deceased donor. The waiting time for a kidney from a living donor is usually shorter, generally resulting in considerably less advanced kidney disease and less time spent on dialysis or preemptive transplantation $[28,29]$. In line with this, we found a strongly significant association between higher cold ischemia time and lower urinary 6-SM excretion. Lastly, multiple studies have demonstrated that RTRs experience poor sleep quality, and a high prevalence of insomnia is found in this population [1,30-32]. Melatonin secretion is an important marker for the circadian rhythm and it signals the "biological night", causing the onset of sleep in humans [8]. The reduced levels of melatonin measured in the RTRs in this study could be influenced by or cause 
the sleep-related problems. This was recognized by the study of Russcher et al. mentioned earlier, where the authors did not find improved sleep quality and melatonin levels after renal transplantation, despite improved renal function [20].

We found that RTRs with diabetic nephropathy as primary renal disease showed clearly reduced to no detectable urinary 6-SM levels. Diabetes and diabetic complications, such as diabetic nephropathy, are associated with the increased presence of oxidative stress after a persistent period of poor glucose control $[33,34]$. Patients with diabetic nephropathy often experience serial problems affecting the eyes, arteries, and peripheral nerves. Currently, transplantation is considered the preferred treatment for patients with ESRD caused by diabetic nephropathy [35]. Why the RTRs with diabetic nephropathy as primary renal disease have lower 6-SM compared to the total RTR population needs to be further investigated. Potential mechanisms could include imbalance in the production of reactive oxygen species, increased vascular calcification, retinopathy, or impaired glucose control. Systemic melatonin synthesis is dependent on the light-dark signals transmitted via the retino-hypothalamic tract [8]. These signals might be absent in patients with severe retinopathy, possibly influencing their melatonin levels [36,37]. One study showed that rats with diabetic nephropathy benefit from treatment with melatonin, most likely via reduction of the oxidative stress, demonstrating a potentially important of role melatonin in the treatment of RTRs with diabetic nephropathy as primary renal disease [38].

The present study showed that reduced urinary 6-SM excretion was associated with an increased risk of all-cause mortality in RTRs independent of age, kidney function, and beta-blocker use. In addition to all-cause mortality, this study showed that low urinary 6-SM levels were independently associated with cardiovascular mortality. Cardiovascular disease is a major cause of death in RTRs, caused by conventional risk factors such as hypertension, diabetes, and renal dysfunction [39]. Reduced urinary 6-SM excretion has been linked to coronary artery disease (CAD); the severity of CAD was negatively associated with urinary 6-SM excretion [40]. Melatonin is known to influence the cardiovascular system via both its antioxidant and anti-inflammatory activities [41]. In rats with renovascular hypertension, the cardiac function improved after treatment with melatonin, implying a possible therapeutic role of melatonin [42]. That melatonin could play a possible important role in kidney transplantation as a therapeutic approach was also demonstrated in a study by Li et al. [43]. In this study, with rats, it was shown that donor pre-conditioning with melatonin protected the kidney graft, likely through its antioxidative properties, improving the survival.

Future investigations should focus on whether supplementation of melatonin in RTRs can prevent the known circadian rhythm sleeping disorders and act as a possible cardiovascular protector by lowering the oxidative stress. In line with this, it would be interesting to examine whether melatonin supplementation affects the mortality rates in RTRs by means of a double-blind randomized control trial.

Some limitations of the study should be noted. The $24 \mathrm{~h}$ urine samples were collected just once, and the conclusions are therefore based on a single measurement. Since the patients were carefully instructed on how to collect the urine, over- and under-collections were unlikely, as previously tested by sensitivity analysis in the same cohort [44]. An additional limitation of this study was the lack of information on sleep reported by or monitored in the RTRs. Subsequently, there were no data available on the use of sleep-related medication or the presence of sleeping disorders such as obstructive sleep apnea syndrome. Even though many studies have shown a link between melatonin and sleep disturbances, we were not able to examine this in our study, and this would a valuable addition for future studies. Additionally, it would have been interesting to examine the association with mortality in healthy individuals, with sufficient follow-up time to underline the findings in the present study. This study could, for instance, be combined with individuals with and without sleep deprivation, to emphasize the results of the current study possibly even more.

One of the major strengths of this study was the use of $24 \mathrm{~h}$ urine for 6-SM analysis, instead of using plasma melatonin or saliva melatonin. Collection of $24 \mathrm{~h}$ urine provides insight over a whole day, rather than at a single time-point, as is the case with plasma melatonin or saliva melatonin. This is particularly of interest because melatonin production is influenced by the circadian rhythm. Furthermore, it has 
been shown that urinary melatonin levels are stable over time within an individual [45]. However, it is important to realize that melatonin levels can be influenced to a certain degree by seasonal changes, working night shifts, and the degree of exposure to artificial light [46,47]. Another strength of this study was the use of LC-MS/MS to measure 6-SM. Compared to immunoassays, LC-MS/MS is more specific, robust, and able to measure low concentrations of urinary 6-SM. Finally, this was an observational study, and it is therefore possible that unmeasured or additional confounding variables might have been present, despite the many potential confounders that we did adjust for.

\section{Conclusions}

In this biobank study, we found significantly lower urinary 6-SM levels in a large group of stable RTRs compared to healthy controls. More importantly, low urinary 6-SM levels in RTRs were independently associated with higher mortality risk, independent of potential confounders. Based on these results, evaluation and management of melatonin metabolism could be considered for improvement of long-term outcome in RTRs.

Author Contributions: Conceptualization, S.J.L.B. and I.P.K.; Methodology, M.v.F.; Formal Analysis, A.v.d.V., I.M., S.J.L.B. and I.P.K.; Investigation, A.v.d.V.; Data Curation, A.W.G.-N and S.J.L.B.; Writing-Original Draft Preparation, A.v.d.V., S.J.L.B and I.P.K.; Writing-Review \& Editing, I.M., M.v.F., A.W.G.-N., S.P.B., S.J.L.B. and I.P.K.; Supervision, M.v.F, S.J.L.B. and I.P.K.; Funding Acquisition, S.J.L.B. All authors have read and agreed to the published version of the manuscript.

Funding: This research was funded by Top Institute Food and Nutrition, grant numbers A-1003 and 16 NH01. The cohort on which the study was based is registered at clinicaltrials.gov as "TransplantLines Food and Nutrition Biobank and Cohort Study (TxL-FN)" with number NCT02811835.

Conflicts of Interest: The authors declare no conflict of interest. The funders had no role in the design of the study; in the collection, analyses, or interpretation of data; in the writing of the manuscript, or in the decision to publish the results.

\section{References}

1. Sabbatini, M.; Crispo, A.; Pisani, A.; Gallo, R.; Cianciaruso, B.; Fuiano, G.; Federico, S.; Andreucci, V.E. Sleep quality in renal transplant patients: A never investigated problem. Nephrol. Dial. Transplant. 2005, 20, 194-198. [CrossRef] [PubMed]

2. Novak, M.; Molnar, M.Z.; Ambrus, C.; Kovacs, A.Z.; Koczy, A.; Remport, A.; Szeifert, L.; Szentkiralyi, A.; Shapiro, C.M.; Kopp, M.S.; et al. Chronic insomnia in kidney transplant recipients. Am. J. Kidney Dis. 2006, 47, 655-665. [CrossRef] [PubMed]

3. Russcher, M.; Koch, B.; Nagtegaal, E.; van der Putten, K.; ter Wee, P.; Gaillard, C. The role of melatonin treatment in chronic kidney disease. Front. Biosci. 2012, 17, 2644-2656. [CrossRef] [PubMed]

4. Maung, S.C.; El Sara, A.; Chapman, C.; Cohen, D.; Cukor, D. Sleep disorders and chronic kidney disease. World J. Nephrol. 2016, 5, 224-232. [CrossRef]

5. Benz, R.L.; Pressman, M.R.; Hovick, E.T.; Peterson, D.D. Potential novel predictors of mortality in end-stage renal disease patients with sleep disorders. Am. J. Kidney Dis. 2000, 35, 1052-1060. [CrossRef]

6. Zhang, H.M.; Zhang, Y. Melatonin: A well-documented antioxidant with conditional pro-oxidant actions. J. Pineal Res. 2014, 57, 131-146. [CrossRef]

7. Cajochen, C.; Krauchi, K.; Wirz-Justice, A. Role of melatonin in the regulation of human circadian rhythms and sleep. J. Neuroendocrinol. 2003, 15, 432-437. [CrossRef]

8. Claustrat, B.; Brun, J.; Chazot, G. The basic physiology and pathophysiology of melatonin. Sleep Med. Rev. 2005, 9, 11-24. [CrossRef]

9. Abeysuriya, R.G.; Lockley, S.W.; Robinson, P.A.; Postnova, S. A unified model of melatonin, 6-sulfatoxymelatonin, and sleep dynamics. J. Pineal Res. 2018, 64, e12474. [CrossRef]

10. Tordjman, S.; Chokron, S.; Delorme, R.; Charrier, A.; Bellissant, E.; Jaafari, N.; Fougerou, C. Melatonin: Pharmacology, Functions and Therapeutic Benefits. Curr. Neuropharmacol. 2017, 15, 434-443. [CrossRef]

11. Koch, B.C.; van der Putten, K.; Van Someren, E.J.; Wielders, J.P.; Ter Wee, P.M.; Nagtegaal, J.E.; Gaillard, C.A. Impairment of endogenous melatonin rhythm is related to the degree of chronic kidney disease (CREAM study). Nephrol. Dial. Transplant. 2010, 25, 513-519. [CrossRef] [PubMed] 
12. Stoschitzky, K.; Sakotnik, A.; Lercher, P.; Zweiker, R.; Maier, R.; Liebmann, P.; Lindner, W. Influence of beta-blockers on melatonin release. Eur. J. Clin. Pharmacol. 1999, 55, 111-115. [CrossRef] [PubMed]

13. McMullan, C.J.; Schernhammer, E.S.; Rimm, E.B.; Hu, F.B.; Forman, J.P. Melatonin secretion and the incidence of type 2 diabetes. JAMA 2013, 309, 1388-1396. [CrossRef] [PubMed]

14. Peschke, E.; Frese, T.; Chankiewitz, E.; Peschke, D.; Preiss, U.; Schneyer, U.; Spessert, R.; Muhlbauer, E. Diabetic Goto Kakizaki rats as well as type 2 diabetic patients show a decreased diurnal serum melatonin level and an increased pancreatic melatonin-receptor status. J. Pineal Res. 2006, 40, 135-143. [CrossRef] [PubMed]

15. Reutrakul, S.; Siwasaranond, N.; Nimitphong, H.; Saetung, S.; Chirakalwasan, N.; Chailurkit, L.O.; Srijaruskul, K.; Ongphiphadhanakul, B.; Thakkinstian, A. Associations between nocturnal urinary 6-sulfatoxymelatonin, obstructive sleep apnea severity and glycemic control in type 2 diabetes. Chronobiol. Int. 2017, 34, 382-392. [CrossRef]

16. Van den Berg, E.; Engberink, M.F.; Brink, E.J.; van Baak, M.A.; Joosten, M.M.; Gans, R.O.; Navis, G.; Bakker, S.J. Dietary acid load and metabolic acidosis in renal transplant recipients. Clin. J. Am. Soc. Nephrol. 2012, 7, 1811-1818. [CrossRef]

17. Van den Berg, E.; Pasch, A.; Westendorp, W.H.; Navis, G.; Brink, E.J.; Gans, R.O.; van Goor, H.; Bakker, S.J. Urinary sulfur metabolites associate with a favorable cardiovascular risk profile and survival benefit in renal transplant recipients. J. Am. Soc. Nephrol. 2014, 25, 1303-1312. [CrossRef]

18. Inker, L.A.; Schmid, C.H.; Tighiouart, H.; Eckfeldt, J.H.; Feldman, H.I.; Greene, T.; Kusek, J.W.; Manzi, J.; Van Lente, F.; Zhang, Y.L.; et al. Estimating Glomerular Filtration Rate from Serum Creatinine and Cystatin, C. N. Engl. J. Med. 2012, 367, 20-29. [CrossRef]

19. Minovic, I.; van der Veen, A.; van Faassen, M.; Riphagen, I.J.; van den Berg, E.; van der Ley, C.; Gomes-Neto, A.W.; Geleijnse, J.M.; Eggersdorfer, M.; Navis, G.J.; et al. Functional vitamin B-6 status and long-term mortality in renal transplant recipients. Am. J. Clin. Nutr. 2017, 106, 1366-1374. [CrossRef]

20. Russcher, M.; Nagtegaal, J.E.; Nurmohamed, S.A.; Koch, B.C.; van der Westerlaken, M.M.; van Someren, E.J.; Bakker, S.J.; Ter Wee, P.M.; Gaillard, C.A. The effects of kidney transplantation on sleep, melatonin, circadian rhythm and quality of life in kidney transplant recipients and living donors. Nephron 2015, 129, 6-15. [CrossRef]

21. Burkhalter, H.; De Geest, S.; Wirz-Justice, A.; Cajochen, C. Melatonin rhythms in renal transplant recipients with sleep-wake disturbances. Chronobiol. Int. 2016, 33, 810-820. [CrossRef] [PubMed]

22. Schmid, H.A.; Raykhtsaum, G. Age-related differences in the structure of human pineal calcium deposits: Results of transmission electron microscopy and mineralographic microanalysis. J. Pineal Res. 1995, 18, 12-20. [CrossRef] [PubMed]

23. Kunz, D.; Schmitz, S.; Mahlberg, R.; Mohr, A.; Stoter, C.; Wolf, K.J.; Herrmann, W.M. A new concept for melatonin deficit: On pineal calcification and melatonin excretion. Neuropsychopharmacology 1999, 21, 765-772. [CrossRef]

24. Blaine, J.; Chonchol, M.; Levi, M. Renal control of calcium, phosphate, and magnesium homeostasis. Clin. J. Am. Soc. Nephrol. 2015, 10, 1257-1272. [CrossRef]

25. Messa, P.; Cafforio, C.; Alfieri, C. Calcium and phosphate changes after renal transplantation. J. Nephrol. 2010, 23 (Suppl. 16), S175.

26. Vipattawat, K.; Kitiyakara, C.; Phakdeekitcharoen, B.; Kantachuvesiri, S.; Sumethkul, V.; Jirasiritham, S.; Stitchantrakul, W.; Disthabanchong, S. Vascular calcification in long-term kidney transplantation. Nephrology 2014, 19, 251-256. [CrossRef]

27. Monteleone, P.; Forziati, D.; Orazzo, C.; Maj, M. Preliminary observations on the suppression of nocturnal plasma melatonin levels by short-term administration of diazepam in humans. J. Pineal Res. 1989, 6, $253-258$. [CrossRef]

28. Jay, C.L.; Dean, P.G.; Helmick, R.A.; Stegall, M.D. Reassessing Preemptive Kidney Transplantation in the United States: Are We Making Progress? Transplantation 2016, 100, 1120-1127. [CrossRef]

29. Davis, C.L.; Delmonico, F.L. Living-donor kidney transplantation: A review of the current practices for the live donor. J. Am. Soc. Nephrol. 2005, 16, 2098-2110. [CrossRef]

30. Burkhalter, H.; Brunner, D.P.; Wirz-Justice, A.; Cajochen, C.; Weaver, T.E.; Steiger, J.; Fehr, T.; Venzin, R.M.; De Geest, S. Self-reported sleep disturbances in renal transplant recipients. BMC Nephrol. 2013, 14, 220. [CrossRef] 
31. Liaveri, P.G.; Dikeos, D.; Ilias, I.; Lygkoni, E.P.; Boletis, I.N.; Skalioti, C.; Paparrigopoulos, T. Quality of sleep in renal transplant recipients and patients on hemodialysis. J. Psychosom. Res. 2017, 93, 96-101. [CrossRef] [PubMed]

32. Molnar, M.Z.; Novak, M.; Mucsi, I. Sleep disorders and quality of life in renal transplant recipients. Int. Urol. Nephrol. 2009, 41, 373-382. [CrossRef] [PubMed]

33. Miranda-Diaz, A.G.; Pazarin-Villasenor, L.; Yanowsky-Escatell, F.G.; Andrade-Sierra, J. Oxidative Stress in Diabetic Nephropathy with Early Chronic Kidney Disease. J. Diabetes Res. 2016, 2016, 7047238. [CrossRef] [PubMed]

34. Pitocco, D.; Tesauro, M.; Alessandro, R.; Ghirlanda, G.; Cardillo, C. Oxidative stress in diabetes: Implications for vascular and other complications. Int. J. Mol. Sci. 2013, 14, 21525-21550. [CrossRef]

35. Noguchi, H.; Kitada, H.; Kaku, K.; Kurihara, K.; Kawanami, S.; Tsuchimoto, A.; Masutani, K.; Nakamura, U.; Tanaka, M. Outcome of renal transplantation in patients with type 2 diabetic nephropathy: A single-center experience. Transplant. Proc. 2015, 47, 608-611. [CrossRef]

36. Hikichi, T.; Tateda, N.; Miura, T. Alteration of melatonin secretion in patients with type 2 diabetes and proliferative diabetic retinopathy. Clin. Ophthalmol. 2011, 5, 655-660. [CrossRef]

37. Chen, W.; Cao, H.; Lu, Q.Y.; Wang, N.; Zhao, S.Z.; Xu, X.; Zheng, Z. Urinary 6-sulfatoxymelatonin level in diabetic retinopathy patients with type 2 diabetes. Int. J. Clin. Exp. Pathol. 2014, 7, 4317-4322.

38. Gumustekin, M.; Tekmen, I.; Guneli, E.; Tugyan, K.; Topcu, A.; Ergonen, A.T.; Ozdemir, M.H.; Uysal, N.; Bediz, C.S. Short-term melatonin treatment improved diabetic nephropathy but did not affect hemorheological changes in diabetic rats. Die Pharm. 2007, 62, 693-698.

39. Neale, J.; Smith, A.C. Cardiovascular risk factors following renal transplant. World J. Transplant. 2015, 5, 183-195. [CrossRef]

40. Girotti, L.; Lago, M.; Ianovsky, O.; Carbajales, J.; Elizari, M.V.; Brusco, L.I.; Cardinali, D.P. Low urinary 6-sulphatoxymelatonin levels in patients with coronary artery disease. J. Pineal Res. 2000, 29, 138-142. [CrossRef]

41. Favero, G.; Franceschetti, L.; Buffoli, B.; Moghadasian, M.H.; Reiter, R.J.; Rodella, L.F.; Rezzani, R. Melatonin: Protection against age-related cardiac pathology. Ageing Res. Rev. 2017, 35, 336-349. [CrossRef] [PubMed]

42. Ersahin, M.; Sehirli, O.; Toklu, H.Z.; Suleymanoglu, S.; Emekli-Alturfan, E.; Yarat, A.; Tatlidede, E.; Yegen, B.C.; Sener, G. Melatonin improves cardiovascular function and ameliorates renal, cardiac and cerebral damage in rats with renovascular hypertension. J. Pineal Res. 2009, 47, 97-106. [CrossRef] [PubMed]

43. Li, Z.; Nickkholgh, A.; Yi, X.; Bruns, H.; Gross, M.L.; Hoffmann, K.; Mohr, E.; Zorn, M.; Buchler, M.W.; Schemmer, P. Melatonin protects kidney grafts from ischemia/reperfusion injury through inhibition of NF-kB and apoptosis after experimental kidney transplantation. J. Pineal Res. 2009, 46, 365-372. [CrossRef] [PubMed]

44. $\quad$ Eisenga, M.F.; Kieneker, L.M.; Soedamah-Muthu, S.S.; van den Berg, E.; Deetman, P.E.; Navis, G.J.; Gans, R.O.; Gaillard, C.A.; Bakker, S.J.; Joosten, M.M. Urinary potassium excretion, renal ammoniagenesis, and risk of graft failure and mortality in renal transplant recipients. Am. J. Clin. Nutr. 2016, 104, 1703-1711. [CrossRef]

45. Mirick, D.K.; Davis, S. Melatonin as a biomarker of circadian dysregulation. Cancer Epidemiol. Biomark. Prev. 2008, 17, 3306-3313. [CrossRef]

46. Claustrat, B.; Leston, J. Melatonin: Physiological effects in humans. Neurochirurgie 2015, 61, 77-84. [CrossRef]

47. Papantoniou, K.; Pozo, O.J.; Espinosa, A.; Marcos, J.; Castano-Vinyals, G.; Basagana, X.; Ribas, F.C.; Mirabent, J.; Martin, J.; Carenys, G.; et al. Circadian variation of melatonin, light exposure, and diurnal preference in day and night shift workers of both sexes. Cancer Epidemiol. Biomark. Prev. 2014, 23, 1176-1186. [CrossRef]

(C) 2020 by the authors. Licensee MDPI, Basel, Switzerland. This article is an open access article distributed under the terms and conditions of the Creative Commons Attribution (CC BY) license (http://creativecommons.org/licenses/by/4.0/). 